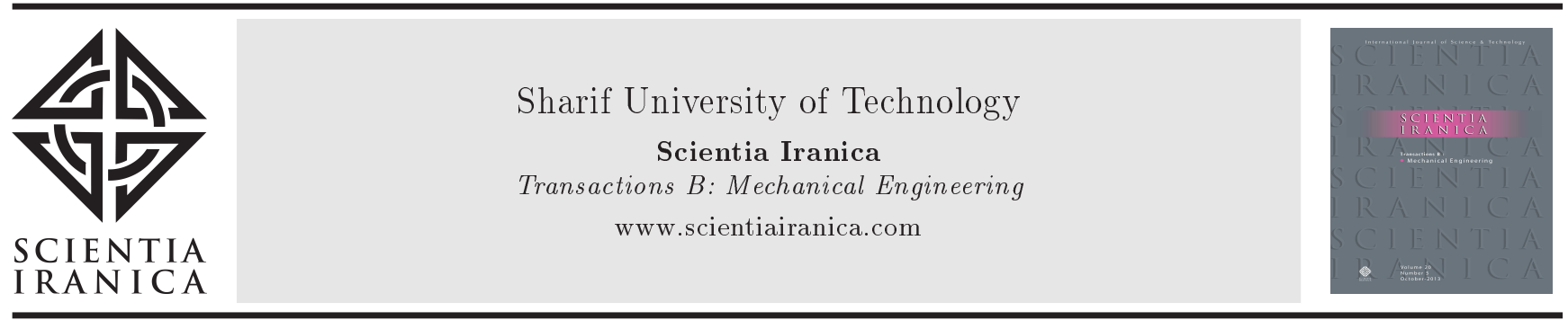

\title{
Impact crushing behavior of foam-filled paraboloid shells using numerical and experimental methods
}

\author{
Sh. Shams ${ }^{a, *}$, H. Haddadpour ${ }^{b}$, H. Tuzandejani ${ }^{b}$, S.A.A. Hosseini ${ }^{c}$, \\ M. Vatanparast ${ }^{\mathrm{d}}$ and S. Zahab \\ a. Department of Aerospace Engineering, Faculty of New Sciences and Technologies, University of Tehran, North Kargar Street, \\ Tehran, Postcode: 1439957131, Iran. \\ b. Department of Aerospace Engineering, Sharif University of Technology, Tehran, P.O. Box 11155-8639, Iran. \\ c. Faculty of Engineering, Kharazmi University, Tehran, P. O. Box 15719-14911, Iran. \\ d. Department of Mechanical Engineering, Iran University of Science \& Technology, Tehran, Iran. \\ e. Department of Aerospace Engineering, Amirkabir University of Technology, Tehran, Iran.
}

Received 4 March 2015; received in revised form 15 June 2016; accepted 14 August 2016

\section{KEYWORDS}

Dynamic response;

Energy absorption;

Impact loading;

Foam-filled parabolic

aluminum tube;

Finite element

analysis.

\begin{abstract}
This paper deals with the dynamic response and energy absorption of foamfilled aluminum parabolic tubes under axial impact loading. The numerical crush analysis of empty and foam-filled tubes is performed using non-linear finite element techniques. The effects of geometrical (wall thickness) and material parameters (foam density and Young's relaxation modulus) on the impact response and energy absorption capacity of foam-filled tube are investigated using numerical models. The results show that the foam properties have significant effect on the crushing behavior, force and impact acceleration magnitude, and energy absorption capacity. Furthermore, there is a critical foam density beyond which the structure loses its energy absorption performance. Experimental results acquired from a test setup are used for validating the Finite-Element Analysis (FEA). There is good agreement between numerical and experimental results.
\end{abstract}

(C) 2017 Sharif University of Technology. All rights reserved.

\section{Introduction}

For better crashworthiness performance, vehicles must protect their occupants by maintaining structural integrity and converting the large amount of kinetic energy into other forms of energy in a controllable and predictable manner in a crash situation.

In recent times, increasing attention has been paid to the use of thin-walled tubes to dissipate energy under adverse effects of impact, hence protecting the structure. It has been recognized that the progressive crushing of thin-walled tubes can absorb greater energy. These structures are used as a means of absorbing

*. Corresponding author. Tel.: +982161115775;

Fax: +982188497324

E-mail address: shahrokh.shams@ut.ac.ir (Sh. Shams) the kinetic energy of a moving body through plastic deformation. Civil and military applications require designing high performance and high energy-absorbing materials and structures. Furthermore, weight is a critical factor for these applications which must be minimized. With the use of thin walls, less material is used and the structural performance per unit weight is improved. For example, in auto sports, new composite cone type nose structures have better performance in head-on and side impact crash cases [1].

Thin-walled tubes of various geometrical shapes, such as circular, square, rectangular, and hat-sections (tapered), are known to be excellent impact energy absorbers due to their progressive axial folding when subject to impact loading. Mamalis et al. [2,3] pointed out that a circular cross-section is more effective in progressive crushing compared to a square or rectan- 
gular cross-section, and a tapered thin-walled tube is preferable to a straight tube as it has a stable loaddeflection response.

In addition, the presence of the filler material in thin-walled tubes seems to improve crush stability and energy absorption capacity [4-6]. One of the earliest investigations on the crushing behavior of thin-walled sections filled with lightweight polyurethane foam (PU foam) was conducted by Lampinen and Jeryan [7]. They concluded that the foam filling stabilizes the deformation of thin-walled tubes. Lu et al. [8] pointed out that the average crushing loads of thin-walled aluminum tubes filled by $\mathrm{PU}$ foam were greater than the sum of the average crushing loads of empty tube and foam individually. Furthermore, Aktay et al. [9] numerically and experimentally investigated the quasistatic axial crushing behavior of PU-foam-filled aluminum thin-walled tubes. They investigated the effect of filling the tube with the foam by considering the effect of the density of the foam filler on the crushing behavior of tubes. They demonstrated that the number of folds formed in the foam-filled tubes and the energy absorptions increased with an increase in the foam filler density.

In addition, some useful studies have been reported on the energy absorption performance of the foam-filled tapered tubes. A tapered thin-walled tube is preferable to a straight tube as it has a stable load-deflection response [10]. Ahmad and Thambiratnam $[11,12]$ performed a parametric study on the metal foam-filled conical tubes under quasi-static axial loading. The conical tube filled with the metallic foam appears to collapse in a steady manner, thus reducing the chances of collapse by global buckling mode. Hence, the foam-filled conical tubes are preferable compared to the empty or foam-filled straight circular tubes for use as energy absorbers. Suna et al. [13] carried out a crashworthiness design for the functionally graded foam-filled thin-walled structure. Ghamarian et al. [14] used quasi-static tests to investigate the crushing behavior of the empty and polyurethane foam-filled end-capped conical tubes. Attia et al. [15] studied the crushing behavior of density-graded foam-filled columns. Zarei and Ghamarian [16] investigated the energy absorption responses of empty and foam-filled cylindrical and conical tubes with shallow spherical caps under quasi-static axial loading. A nonlinear finite-element dynamic analysis was carried out to numerically analyze the problem. Andersson and Liedberg [17] showed that simulation of the crushing of composite structures is complex to run explicitly due to some uncertainties such as material model parameters instead of the real physics, badly tuned contact definition, incorrect damping in the model, and mechanism of delaminating. Djamaluddina et al. [18] studied the crashworthiness design for thin-walled aluminum foam- filled circular tubes using finite-element analysis for empty and foam-filled double and single tubes under pure axial impact. They used some criteria, such as peak crushing force and specific energy absorption, at different impact velocities under axial impact loadings. They showed that increasing the impact velocity brings about an increase in the specific energy absorption and peak crushing force; they also demonstrated that double-cylindrical tubes have good potential energy absorbing attributes in crashworthiness structure applications. Rajak1 et al. [19] investigated the compressive deformation behavior of square, rectangular, and round aluminum foam-filled and empty steel samples at room temperature. They showed that the round crosssection has more energy absorption than the square and rectangular cross-sections; for round section tubes, the amount of energy absorption is greater with low foam density.

Although foam-filled tubes have important applications in aerospace and automobile industries, a review of literature shows that the dynamical behavior of parabolic aluminum tubes under impact loading has not been yet investigated. By using numerical and experimental methods, in the present study, we investigate the dynamic response and the energy absorption of the empty and foam-filled parabolic aluminum tubes under axial impact loading. Nonlinear finite-element numerical simulation has been performed to study the dynamical behavior of the tube. A sensitivity analysis has been performed by varying the foam properties and wall thickness of tube to quantify the energy absorption behavior. The effect of Young's relaxation modulus (ED) of the PU foam on the energy absorption capacity and the impact acceleration is specially investigated as a new parameter. The primary outcome of this study is the new design information on the energy absorption performance of the foam-filled parabolic tubes which also facilitates the development of design guideline for such tubes as energy absorbers in the impact applications, not investigated previously in detail.

\section{Finite-element modeling}

The finite-element models of the empty and foam-filled parabolic tubes are developed using the non-linear finite-element LS-DYNA code [20]. The geometric properties of the tube are shown in Table 1. Figure 1 shows the mesh of the foam and tube skin. The mesh size used for modeling is presented in Table 2. Solid

Table 1. Geometric properties of the aluminum tube.

\begin{tabular}{cccc}
\hline $\begin{array}{c}\text { Top } \\
\text { diameter } \\
(\mathbf{m m})\end{array}$ & $\begin{array}{c}\text { Base } \\
\text { diameter } \\
(\mathbf{m m})\end{array}$ & $\begin{array}{c}\text { Wall } \\
\text { thickness } \\
(\mathbf{m m})\end{array}$ & $\begin{array}{c}\text { Height } \\
(\mathbf{m m})\end{array}$ \\
\hline 75 & 215 & 0.889 & 530 \\
\hline
\end{tabular}


Table 2. Mesh size of FEM modeling.

\begin{tabular}{clll}
\hline $\begin{array}{c}\text { Type of } \\
\text { mesh }\end{array}$ & $\begin{array}{c}\text { Direction of } \\
\text { mesh }\end{array}$ & $\begin{array}{c}\text { No. of } \\
\text { elements }\end{array}$ & $\begin{array}{c}\text { Mesh } \\
\text { size rate }\end{array}$ \\
\hline Skin mesh & Environmental & 64 & 1 \\
Skin mesh & Height & 128 & 0.99 \\
Foam mesh & Environmental & 32 & 1 \\
Foam mesh & Height & 32 & 0.97 \\
\hline
\end{tabular}

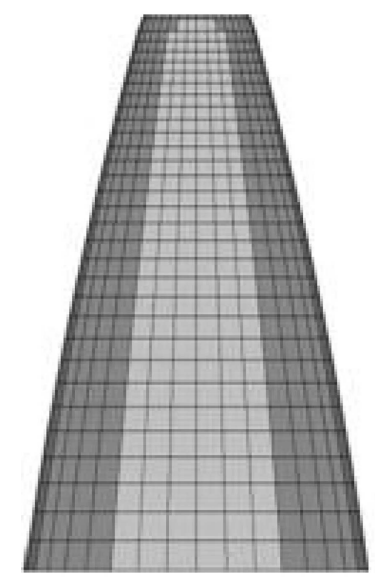

(a) Foam mesh

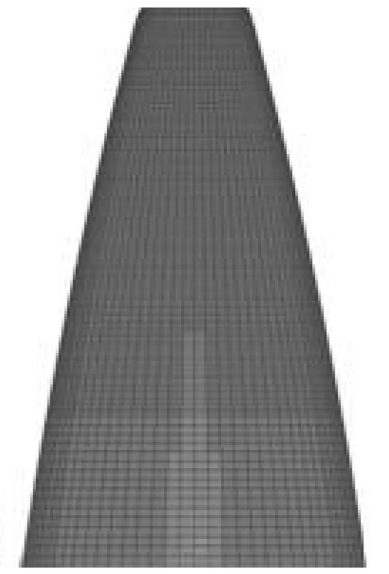

(b) Tube skin mesh
Figure 1. Finite element mesh.

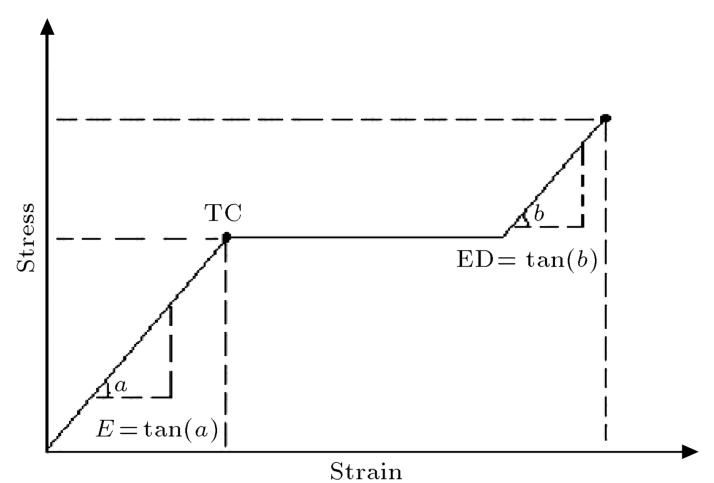

Figure 2. Definition of PU foam's parameters.

elements are used to simulate the foam, while the shell element is used for the tube skin. In order to reduce the computational cost, a coarser mesh is used for the foam compared to the one used for the shell. In order to account for the contact between the foam and tube, an "automatic surface-to-surface" contact element is defined. A "single surface" contact element is used to avoid the effect of the tube wall. Also, a rigid surface is defined for the impact plane. A viscoplastic material model, named "Piecewise Linear Plasticity (Isotropic)" (Material Number 24), behaves as an elasto-plastic material applied to FEM mesh. For this material, stress-strain relationship curve is defined (as shown in Figures 2 and 3 ) to predict material behavior in various contact speeds regarding a viscoplastic strain rate. In addition, by defining the strain failure criteria,

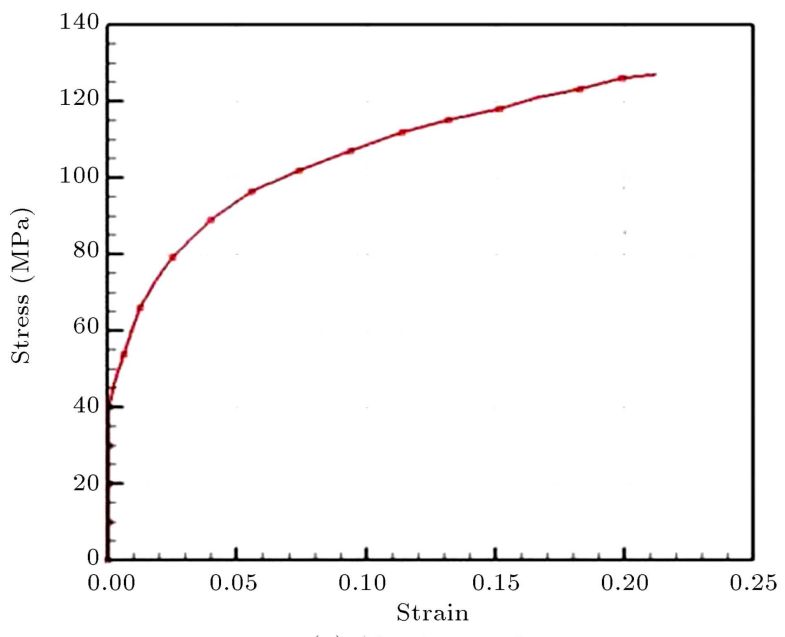

(a) Aluminum tube

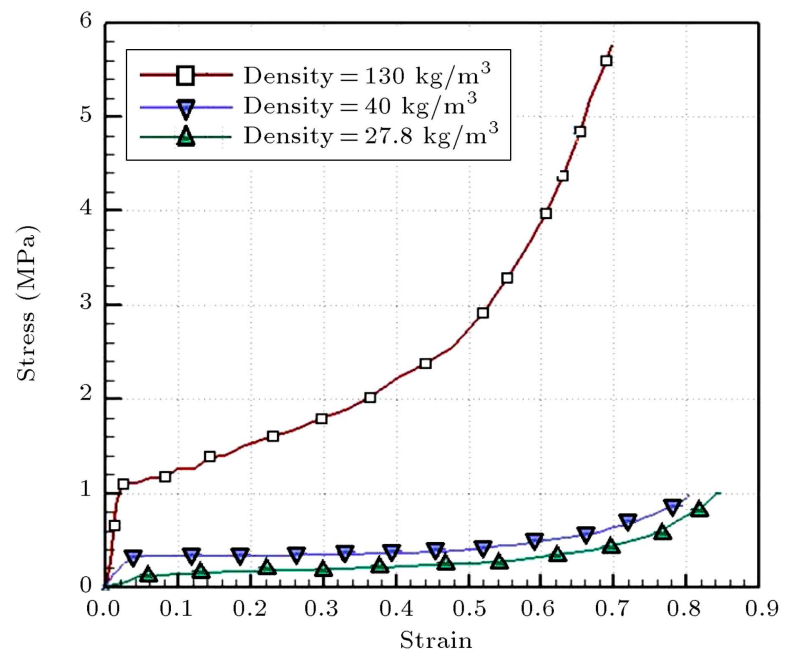

(b) Three density types of PU foam

Figure 3. Stress-strain curve for (a) the aluminum tube and (b) the PU foam.

the failed elements (which are specified by exceeding their strain from the defined limit) will be eliminated from the elements list.

The constitutive equation based on radial return plasticity can be defined as follows [20]:

$$
\begin{aligned}
& \dot{s}_{i j}-s_{i p} \Omega_{p j}-s_{j p} \Omega_{p i}=2 G \dot{\varepsilon}_{i j}^{\prime}, \\
& s_{i j}=\sigma_{i j}+p \delta_{i j}, \\
& p=-\frac{1}{3} \sigma_{i j} \delta_{i j}, \\
& \dot{\varepsilon}_{i j}^{\prime}=\dot{\varepsilon}_{i j}-\frac{1}{3} \dot{\varepsilon}_{V}, \\
& \dot{\varepsilon}_{V}=\dot{\varepsilon}_{i j} \delta_{i j},
\end{aligned}
$$

where $\dot{s}_{i j}$ is deviatoric stress rate tensor, $s_{i j}$ is deviatoric stress tensor, $\Omega_{i j}$ is rigid rotation tensor, $\dot{\varepsilon}_{i j}^{\prime}$ is deviatoric strain rate tensor, $G$ is shear modulus, $\sigma_{i j}$ 
Table 3. Mechanical properties of the aluminum tube.

\begin{tabular}{cccc}
\hline $\begin{array}{c}\text { Ultimate } \\
\text { stress } \\
(\mathbf{G P a})\end{array}$ & $\begin{array}{c}\text { Yield } \\
\text { stress } \\
(\mathbf{G P a})\end{array}$ & $\begin{array}{c}\text { Modulus of } \\
\text { elasticity } \\
(\mathbf{G P a})\end{array}$ & $\begin{array}{c}\text { Density } \\
\mathbf{k g} / \mathbf{m m}^{3}\end{array}$ \\
\hline 0.13 & 0.041 & 69 & $2.7 \mathrm{e}-6$ \\
\hline
\end{tabular}

is Cauchy stress tensor, $p$ is hydrostatic pressure, $\delta_{i j}$ is Kronecker delta tensor, $\dot{\varepsilon}_{i j}$ is strain rate tensor, and $\dot{\varepsilon}_{V}$ is volumetric strain rate.

The mechanical properties of aluminum are shown in Table 3. Parameters describing the characteristics of the foam and their corresponding definitions are shown in Figure 2, respectively. The stress-strain curves of the parabolic aluminum tube and those of the PU foam are shown in Figure 3(a) and (b), respectively. They are modeled with some piecewise linear elastic-plastic material in LS-DYNA. Other material properties of PU foam are tabulated in Table 4.

It should be noted that the stress in the foam depends on the strain rate. To simplify the numerical simulations, a nominal stress-strain curve for the foam is assumed; that is, it is assumed that the foam in deformation process has a fixed average stress-strain curve. Since the change of deformation rate is not very high [21], this assumption is acceptable.

The effects of the variation of the mentioned parameters on the impact response are simulated using FEM. For validation of the finite-element analysis, experimental results of the empty and foam-filled parabolic tubes under axial impact loading, acquired from a drop test setup, are used.

\section{Drop test facility}

The required equipment for the drop test setup is as follows: tube installation fixture, drop stand system, foam-filled tube, and bolts for linking the tube to

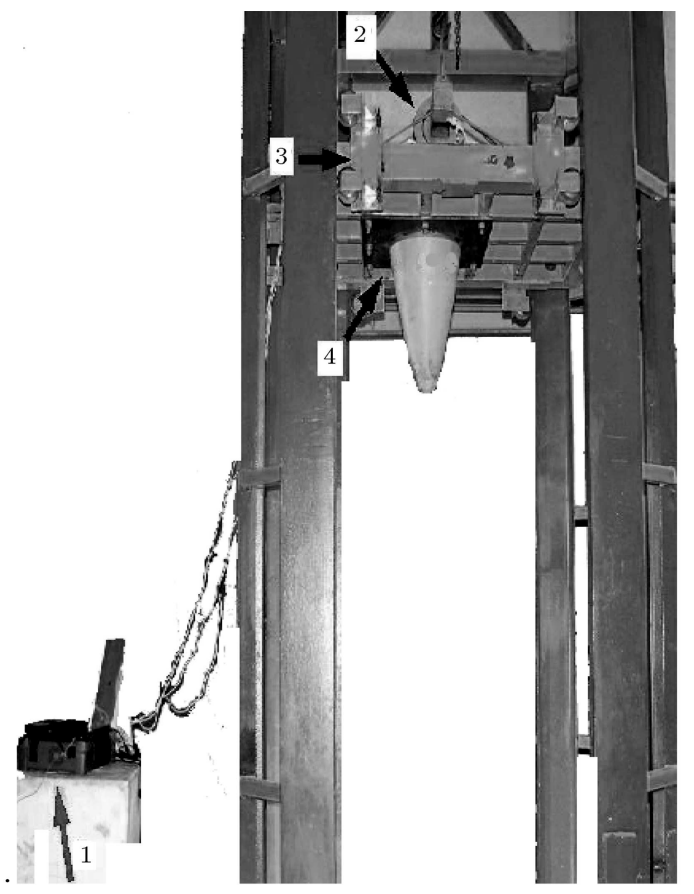

Figure 4. Schematic of drop test apparatus: (1) data acquisition system, (2) lifter mechanism, (3) frame, and (4) parabolic tube.

the fixture, rigid steel surface, balance weight, lifter, accelerometer sensor, high-speed camera, lead mass, and data acquisition system.

As shown in Figure 4(a), a schematic of drop test apparatus consists of:

1. Data acquisition system;

2. Lifter mechanism;

3. Frame;

4. Parabolic tube.

Different values of mass, height, and tube configurations are implemented by experimental setups.

Table 4. Characteristics of the PU foam and tube.

\begin{tabular}{|c|c|c|c|c|c|c|}
\hline \multirow[b]{2}{*}{ \# } & \multirow[b]{2}{*}{ Model } & \multicolumn{4}{|c|}{ PU foam material } & \multirow{2}{*}{$\begin{array}{c}\text { Tube } \\
\text { thickness } \\
(\mathrm{mm})\end{array}$} \\
\hline & & $\begin{array}{l}\text { Density } \\
\mathrm{kg} / \mathrm{mm}^{3}\end{array}$ & $\begin{array}{c}E \\
(\mathrm{GPa}) \\
\end{array}$ & $\begin{array}{c}T c \\
(\mathrm{GPa})\end{array}$ & $\begin{array}{c}E D \\
(\mathrm{GPa})\end{array}$ & \\
\hline 1 & Wall thickness_1 & $4.00 \mathrm{E}-08$ & 0.014 & 0.0009 & 0.00001 & 0.635 \\
\hline 2 & Wall thickness_2 & $4.00 \mathrm{E}-08$ & 0.014 & 0.0009 & 0.00001 & 0.889 \\
\hline 3 & Wall thickness_3 & $4.00 \mathrm{E}-08$ & 0.014 & 0.0009 & 0.00001 & 1.27 \\
\hline 4 & Empty tube & 0 & 0 & 0 & 0 & 0.889 \\
\hline 5 & Foam density_1 & $2.78 \mathrm{E}-08$ & 0.0021 & 0.0009 & 0.00001 & 0.889 \\
\hline 6 & Foam density_2 & $4.00 \mathrm{E}-08$ & 0.014 & 0.0009 & 0.00001 & 0.889 \\
\hline 7 & Foam density_3 & $1.30 \mathrm{E}-07$ & 0.060 & 0.0009 & 0.00001 & 0.889 \\
\hline 8 & Foam ED_1 & $4.00 \mathrm{E}-08$ & 0.014 & 0.0009 & 0.005 & 0.889 \\
\hline 9 & Foam ED_2 & $4.00 \mathrm{E}-08$ & 0.014 & 0.0009 & 0.01 & 0.889 \\
\hline 10 & Foam ED_2 & $4.00 \mathrm{E}-08$ & 0.014 & 0.0009 & 0.02 & 0.889 \\
\hline
\end{tabular}



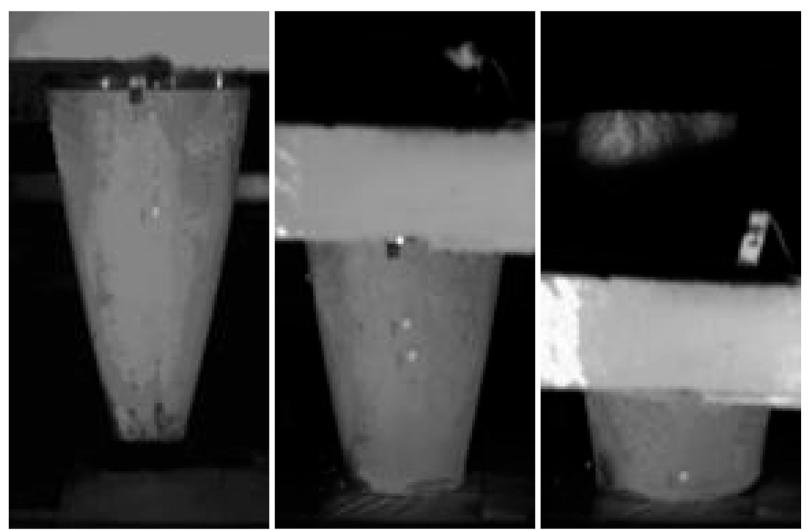

Figure 5. Sequence of the impact of tube to the rigid plane during the drop test (left to right).

Acceleration measurement of dropped mass is carried out by vibration recorder. Vibration recorder consists of data acquisition, cable, sensor, laptop, and related software. Data acquisition system and related software are manufactured by OROS. Accelerometer sensors are manufactured by Endevco. After tube installation, the system is lifted to a specific height, and then it is released which impacts the rigid surface. Sensors record the temporal acceleration of the mass during impacts. In addition, the deformation sequences of the tube are extracted from the high-speed images using a high-speed camera and image processor software.

Some of the sequential images of the tube during the drop test, taken by the high-speed camera, are shown in Figure 5.

\section{Validation of the finite-element model}

The FE model for the foam-filled parabolic tube is validated by experimental results. The experimental and $\mathrm{FE}$ analysis images of the deformed tube are compared in Figure 6. Also, the experimental and FE analysis results, including mass displacement due to the impact and impact acceleration, are compared in Table 5, Figures 7, and 8. There is good agreement between the $\mathrm{FE}$ results and experimental ones.

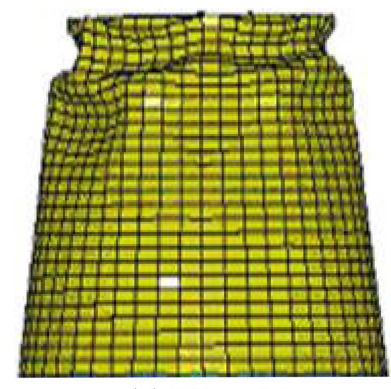

(a) FE model

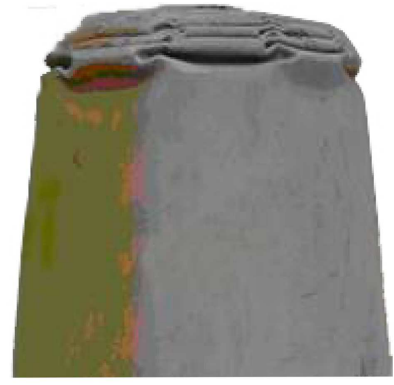

(b) Experimental sample
Figure 6. Comparison between the FE and experimental deformation results for the foam-filled tube.
Table 5. Comparison between the FEM and experiment results of the foam-filled tube.

\begin{tabular}{lccc}
\hline Result & $\begin{array}{c}\text { Max impact } \\
\text { acceleration } \\
\mathbf{g}\left(\mathbf{m} / \mathbf{s}^{\mathbf{2}}\right)\end{array}$ & $\begin{array}{c}\text { Max impact } \\
\text { deformation } \\
(\mathbf{m m})\end{array}$ & $\begin{array}{c}\text { Max } \\
\text { impact } \\
\text { time } \\
(\mathbf{m s})\end{array}$ \\
\hline Experiment & 18.9 & 395 & 57 \\
FEM & 18.5 & 389 & 57.5 \\
$\frac{\text { Exper.-FEM }}{\text { Experiment }}$ & $2 \%$ & $1.5 \%$ & $-0.9 \%$ \\
\hline
\end{tabular}

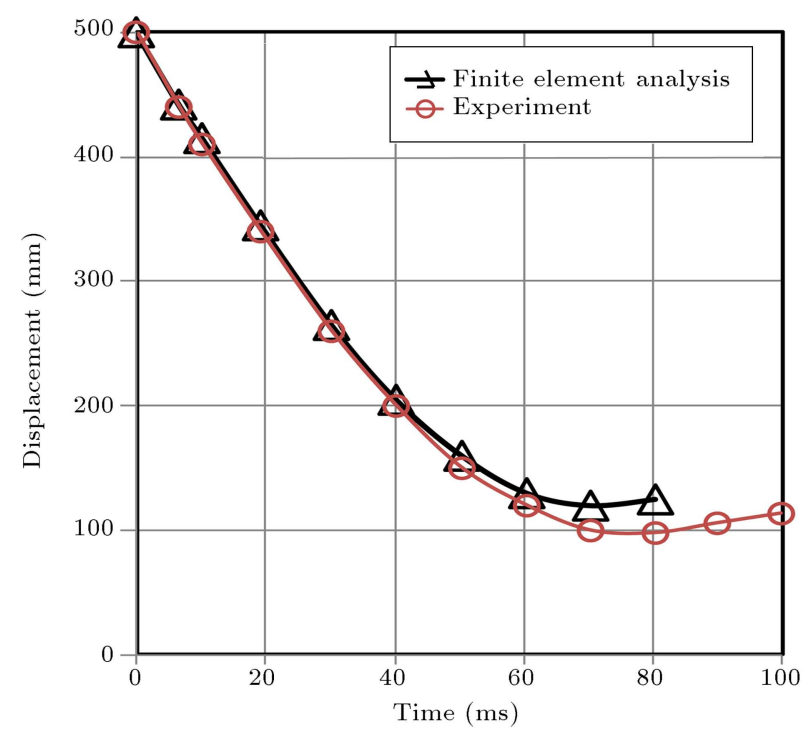

Figure 7. Comparison between the FE and experimental displacement results for the end-mass of the foam-filled tube.

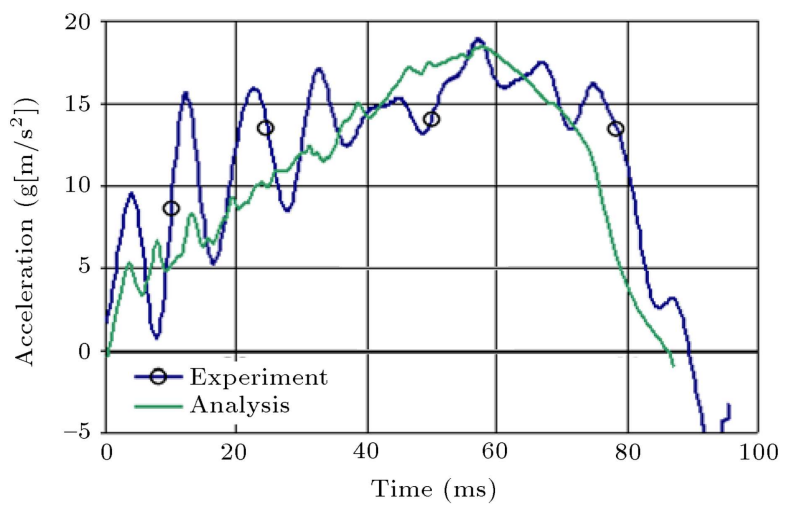

Figure 8. Comparison between the FEM and experimental acceleration results for the end-mass of the foam-filled tube.

\section{Effects of the wall thickness on the impact characteristics of the tube}

Three models are simulated to study the effect of wall thickness on the impact acceleration and the fold formation of the parabolic tube. The foam properties are kept the same, and the input parameter is wall thickness whose details are described in Table 4. 


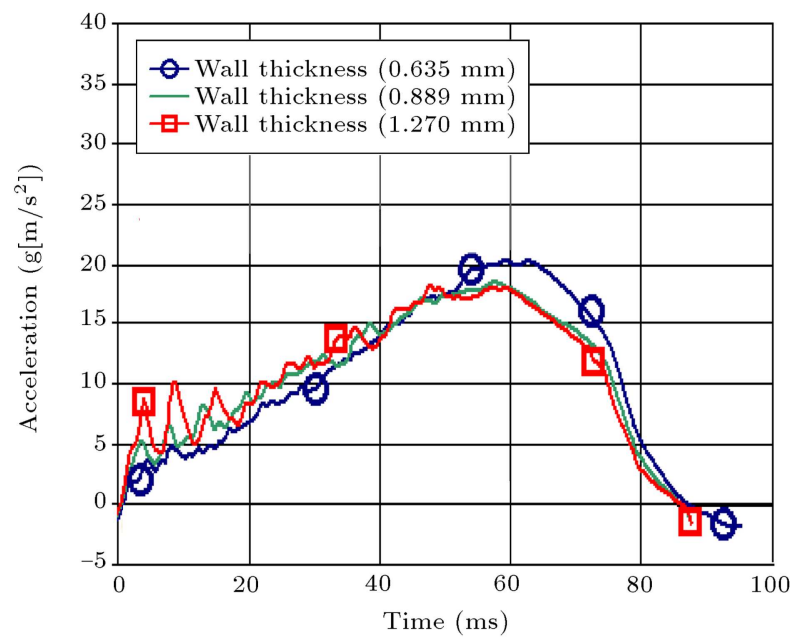

Figure 9. The effect of wall thickness on acceleration results.

Figure 9 shows that although the impact acceleration does not increase notably when the wall thickness increases, the length of the folds increases. Thus, the number of the folds decreases which leads to an increase in the energy absorption capacity and required load for the formation of the folds in the tube. The effect of wall thickness on the number of folds can be seen in Figure 9, where it is observed that the fold numbers in model 3 (wall thickness $=1.27 \mathrm{~mm}$ ) are less than model 2 (wall thickness $=0.889 \mathrm{~mm}$ ). Of course, this increase is negligible in these models. However, when the wall thickness is very small, a sudden increase occurs in the force and impact acceleration curve at the final stage of the impact process.

According to Figure 10, localization phenomena (such as Aluminum and foam delaminating or local picks in acceleration-time curves) are observed in the results. These phenomena are mainly due to the difference between material properties of the foam and aluminum. As the strain rate of the foam and aluminum is considerably different, in the folding sequence, different parts of specimen deform in different deformation rates, and consequently localization phenomena take

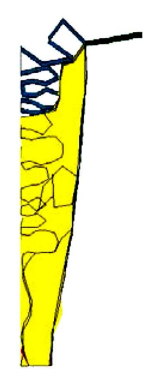

(1)

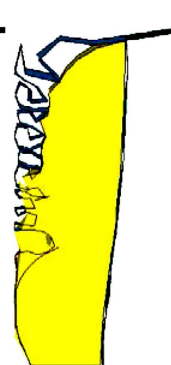

(2)

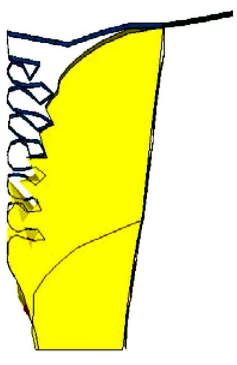

(3) (a)

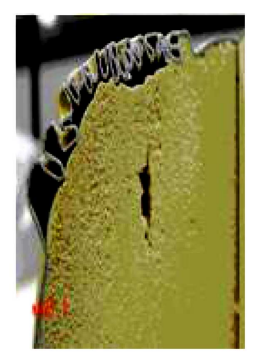

(b)

Figure 10. (a) Tube folding for three FE models presented in Table 4. (b) Sample tested for experimental confirmation.

place. Experimental results completely confirm this assertion.

\section{Effects of the foam density on the impact characteristics of the tube}

In this part, the effect of foam density on the impact characteristics of tube is studied for constant geometrical dimensions. Figure 11 shows the fold formation of parabolic tube as a function of foam density. Other parameters are presented in Table 4 . The effects of changing the foam density on the impact response of the foam-filled parabolic tubes are evaluated at the impact velocity of $10 \mathrm{~m} / \mathrm{s}$.

Figures 12 and 13 show the displacement and acceleration of the parabolic tube under axial impact versus time. Figure 12 compares the displacement of the empty tube with the foam-filled models. According to this figure, by increasing the foam density, maximum deformation of tube decreases. In Figures 13 and 14, the temporal acceleration and internal energy behavior of tubes, regarding the foam density, are presented.

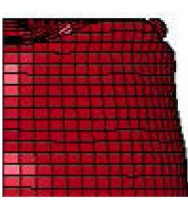

(a)

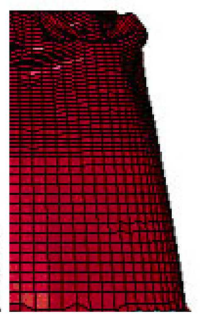

(b)

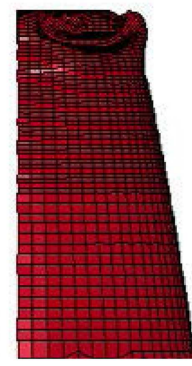

(c)

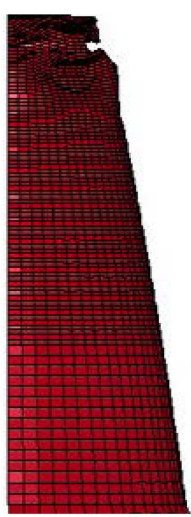

(d)
Figure 11. Effect of the foam density on the fold formation of foam-filled parabolic tube: (a) Empty tube, (b) $\rho_{f}=27.8 \mathrm{~kg} / \mathrm{m}^{3}$, (c) $\rho_{f}=40 \mathrm{~kg} / \mathrm{m}^{3}$, and (d) $\rho_{f}=130 \mathrm{~kg} / \mathrm{m}^{3}$.

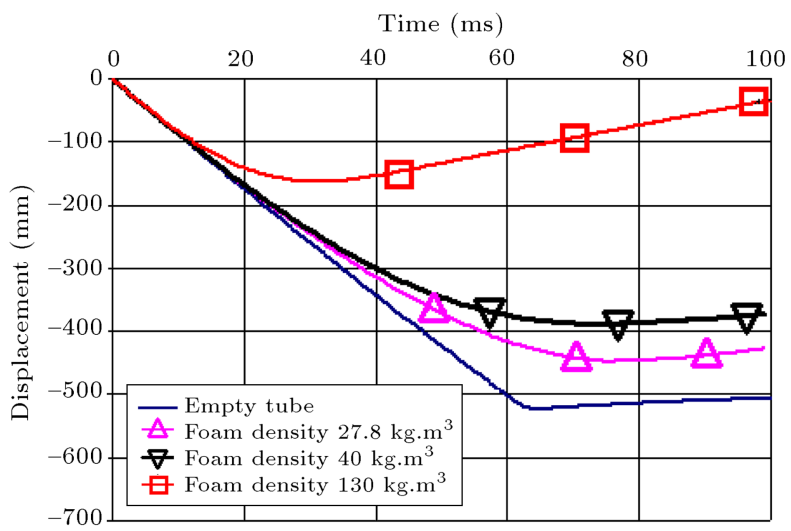

Figure 12. Effect of the foam density on the displacement of foam-filled parabolic tube. 


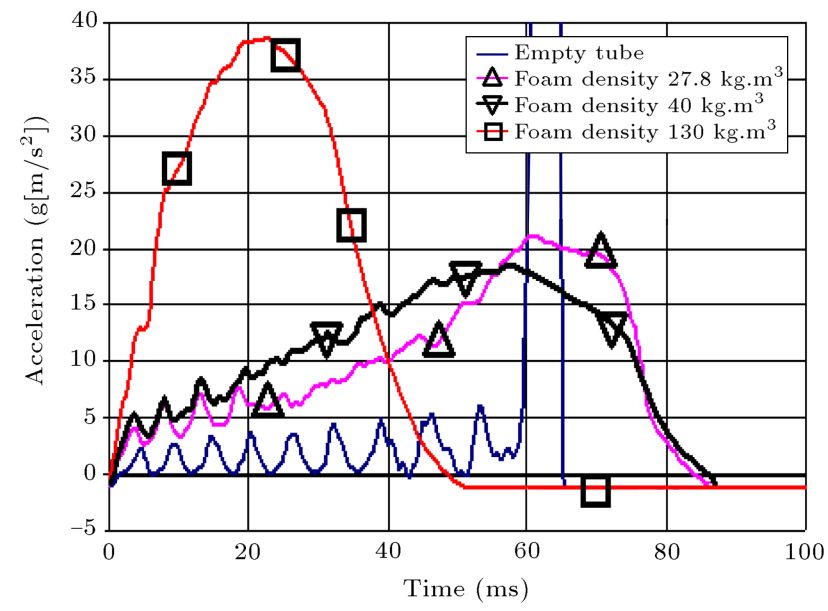

Figure 13. Effect of the foam density on the acceleration of empty/foam-filled parabolic tube.

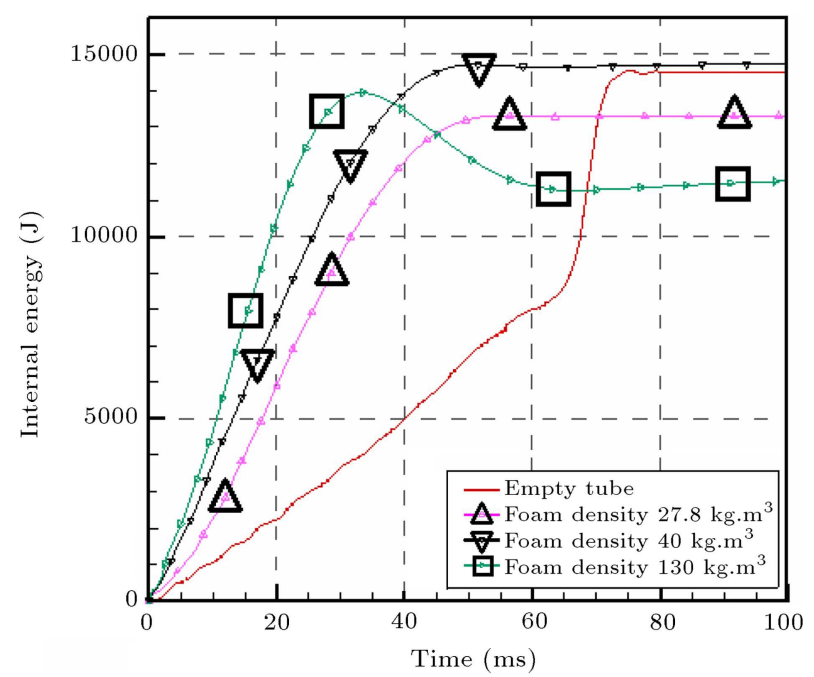

Figure 14. Effect of the foam density on the internal energy of empty/foam-filled parabolic tube.

Regarding these two figures, in the case of foam density of $130 \mathrm{~kg} / \mathrm{m}^{3}$, the maximum acceleration and maximum internal energy increase suddenly. It can be due to greater rigidity of tube with foam density of $130 \mathrm{~kg} / \mathrm{m}^{3}$ at the primary stages of folding. In addition, for empty tube, maximum acceleration occurred at the final stage of folding where this tube folds in the case of maximum deformation and acts as a rigid wrinkled solid; therefore, this rigid object transfers all the remaining impact energy to sensors, straightly. So, foam density of $40 \mathrm{~km} / \mathrm{m}^{3}$ can be chosen as an optimum foam density whose maximum acceleration is the least and its energy absorption is maximum.

Figures 15 to 17 show maximum accelerations, displacement and acceleration time as a function of foam density. It is observed from these figures that the foam with the densities of 27.8 and 40 has similar behavior, while according to Figure 18, the maximum absorbed energy in the foam with the density of $\rho_{f}=$

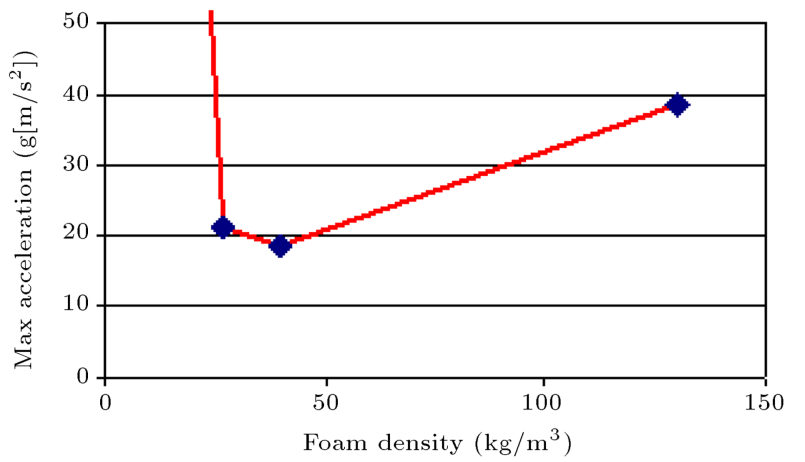

Figure 15. Effect of the foam density on maximum acceleration of foam-filled parabolic tube.

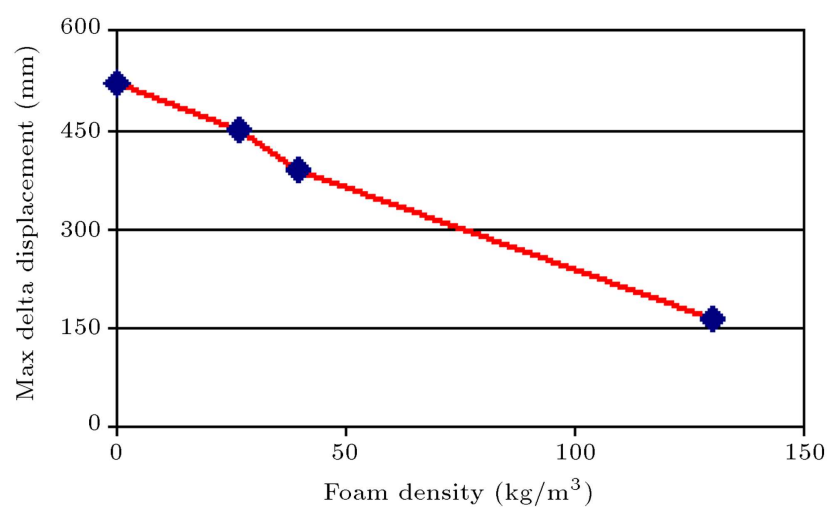

Figure 16. Effect of the foam density on maximum displacement of foam-filled parabolic tube.

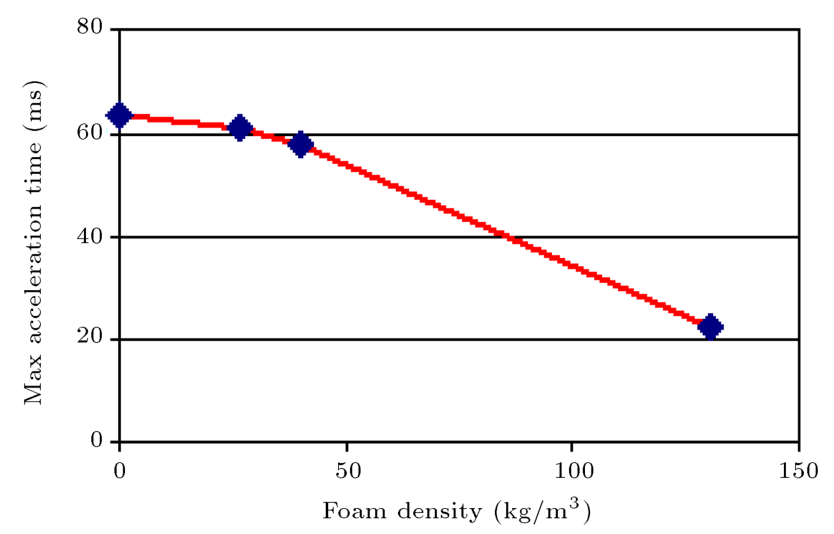

Figure 17. Effect of the foam density on maximum acceleration time of foam-filled parabolic tube.

$40 \mathrm{~kg} / \mathrm{m}^{3}$ is maximum. The results show that as the foam density increases, there will be optimum density at which the maximum acceleration finds its minimum value. This optimum foam density is observed in the tube with foam density of $40 \mathrm{~kg} / \mathrm{m}^{3}$.

\section{Effects of the Young's relaxation modulus on the impact characteristics of the tube}

In this section, the effect of the Young's relaxation modulus (see Figure 2 for ED parameter) is inves- 


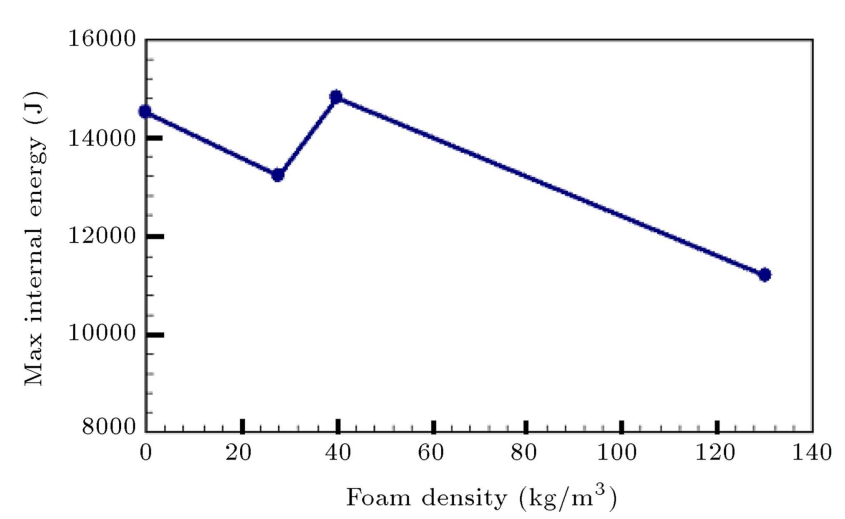

Figure 18. Effect of the foam density on maximum internal energy of foam-filled parabolic tube.

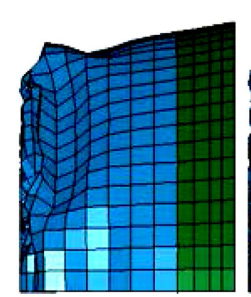

(a) $\mathrm{ED}=0.005$

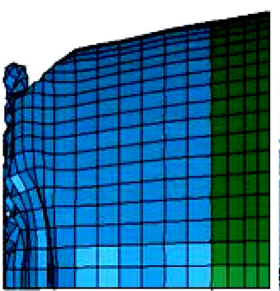

(b) $\mathrm{ED}=0.010$

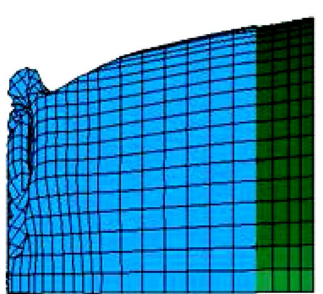

(c) $\mathrm{ED}=0.020$
Figure 19. Effects of the Young's relaxation modulus on the fold formation of foam-filled parabolic tube.

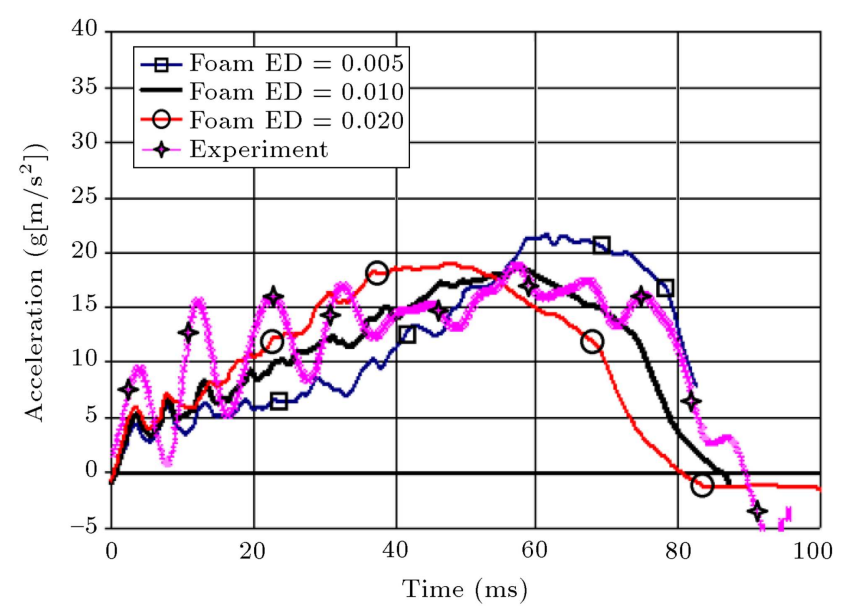

Figure 20. Effects of the Young's relaxation modulus on acceleration of foam-filled parabolic tube.

tigated. For meaningful comparison, the dimension and thickness of tubes are the same, and the Young's relaxation modulus (ED) varies as an input parameter. The details are described in Table 4. Figure 19 shows the fold formation of models after $60 \mathrm{~ms}$. In this figure, it can be seen that by increasing the ED, the number of the folds decreases. The results are validated through conducting an experiment, demonstrated in Figure 20. In this figure, the foam model, named ED_0.01, has the closest impact acceleration behavior to the experimental model.

\section{Conclusion}

This paper investigated and described the crushing and energy absorption behaviors of empty and foamfilled parabolic tubes under quasi-static axial loading using validated FE models and experimental results. Comparing the analysis and experimental results showed good agreement between them. It was due to using the proper material properties captured from the material analysis. The effect of wall thickness on the number of folds was investigated. It was observed that by increasing wall thickness, numbers of folding layers are decreasing. In addition, when the wall thickness is very thin, due to a weakness in the structure stiffness, the force and acceleration curve increase suddenly at the final stage of the impact process. The effect of variations in foam properties has also been considered. The results showed that by increasing the foam density, optimum density can be found at which the maximum acceleration finds its minimum value. Finally, effects of the Young's relaxation modulus on the impact characteristics of the tube were studied. The results demonstrated that as Young's relaxation modulus increases, the number of the folds decreases. It can be concluded that due to higher rigidity at the final stage of compression of the foam, less deformation in the foam-filled tube occurs. In addition, the temporal acceleration results show that by increasing Young's relaxation modulus, maximum acceleration occurs at a shorter time due to increasing the rigidity during the final stage of deformation. Therefore, it can be concluded that foamfilled parabolic tube is superior to empty parabolic tube in energy absorption performance based on the energy absorption capacity, impact acceleration, and stability of crushing response. Also, the energy absorbed for a foam-filled parabolic tube can be maximized by (i) increasing the wall thickness and (ii) increasing the density of foam filler to optimum density, as very large foam densities might adversely affect the energy absorption performance due to its behavior as a rigid filler. The proper choice of foam density is, therefore, important as density has very important role in foam structural characteristics. Moreover, this choice should be made based on the innovation and experience of the designer, as this type of energy absorber has not been investigated previously in detail.

\section{References}

1. Wijayathunga, N., Webb, D.C. and Kormi, K.FE "Simulation of head-on and side impact crash analysis between a nose cone type structure and rigid objects", Int. J. Crashworthines, 8, pp. 53-61 (2003).

2. Mamalis, A.G., Johnson, W. and Viegelahn, G.L. "The crumpling of steel thin-walled tubes and frusta under axial compression at elevated strain rates: some 
experimental results", Int. J. Mech. Sci., 26, pp. 537548 (1984).

3. Mamalis, A.G., Manolakos, D.E., Loannidis, M.B. and Kostazos, P.K. "Numerical simulation of thin-walled metallic circular frusta subjected to axial loading", Int. J. Crashworthines, 10, pp. 505-513 (2005).

4. Seitzberger, M., Rammerstorfer, F.G., Degischer, H.P. and Gradinger, R. "Crushing of axially compressed steel tubes filled with aluminium foam", Acta. Mech., 125, pp. 93-105 (1997).

5. Santosa, S.P., Wierzbicki, T., Hanssen, A.G. and Langseth, M. "Experimental and numerical studies of foam-filled sections", Int. J. Impact Eng., 24, pp. 509534 (2000).

6. Borvik, T., Hopperstad, O.S., Reyes, A., Langseth, M., Solomos, G. and Dyngeland, T. "Empty and foamfilled circular aluminium tubes subjected to axial and oblique quasistatic loading", Int. J. Crashworthines, $\mathbf{8}$, pp. 481-494 (2003).

7. Lampinen, B.H. and Jeryan, R.A. "Effectiveness of polyurethane foam in energy absorbing structures", SAE paper 820494 (1982).

8. Lu, S.R., Guillow, G. and Grezbieta, R.H. "Quasistatic compression of thin-walled circular aluminum tubes", Int. J. Mech. Sci., 43, pp. 2103-2123 (2001).

9. Aktay, L., Toksoy, A.K. and Guden, M. "Quasi-static axial crushing of extruded polystyrene foam-filled thinwalled aluminum tubes: Experimental and numerical analysis", Mater Design, 27, pp. 556-565 (2006).

10. Nagel, G.M. and Thambiratnam, D.P. "A numerical study on the impact response and energy absorption of tapered thin-walled tubes", Int. J. Mech. Sci., 46, pp. 201-216 (2004)

11. Ahmad, Z. and Thambiratnam, D.P. "Dynamic computer simulation and energy absorption of foam-filled conical tubes under axial impact loading", Comput. Struct., 87, pp. 186-197 (2009).

12. Ahmad, Z. and Thambiratnam, D.P. "Crushing response of foam-filled conical tubes under quasi-static axial loading", Mater Design, 30, pp. 2393-2403 (2009).

13. Suna, G., Lia, G., Houa, S., Zhoub, S., Lib, W. and Lib, Q. "Crashworthiness design for functionally graded foam-filled thin-walled structures", Materials Science and Engineering: A, 527, pp. 1911-1919 (2010).

14. Ghamariana, A., Zareib, H.R. and Abadi, M.T. "Experimental and numerical crashworthiness investigation of empty and foam-filled end-capped conical tubes", Thin-Walled Structures, 49, pp. 1312-1319 (2011).

15. Attia, M.S., Meguid, S.A. and Nouraei, H. "Nonlinear finite element analysis of the crush behaviour of functionally graded foam-filled columns", Finite Elements in Analysis and Design, 61, pp. 50-59 (2012).
16. Zarei, H.R. and Ghamarian, A. "Experimental and numerical crashworthiness investigation of empty and foam-filled thin-walled tubes with shallow spherical caps", Experimental Mechanics, 54, pp. 115-126 (2014).

17. Andersson, M. and Liedberg, P. "Crash behavior of composite structures", Master's Thesis in Applied Mechanics, Department of Applied Mechanics, Division of Material and Computational Mechanics, Chalmers University of Technology, Goteborg, Sweden (2014).

18. Djamaluddina, F., Abdullahb, Sh., Ariffin, A.K. and Nopiahd, Z.M. "Multi objective optimization of foamfilled circular tubes for quasi-static and dynamic responses", Latin American Journal of Solids and Structures, 12, pp. 1126-1143 (2015).

19. Rajak1, D.K., Kumaraswamidhas, L.A. and Das, S., "Energy absorption capacity of empty and foam filled mild steel tube under low strain rate at room temperature", Advanced Materials Letters, 6, pp. 548-553 (2015).

20. Hallquist, J.O., LS-DYNA 3D: Theoretical Manual, Livermore: Livermore Software Technology Corporation (2006).

21. Jeong, K.Y., Cheon, S.S. and Munshi, M.B. "A constitutive model for polyurethane foam with strain rate sensitivity", Journal of Mechanical Science and Technology, 26, pp. 2033-2038 (2012).

\section{Biographies}

Shahrokh Shams is currently an Assistant Professor at Department of Aerospace Engineering, Faculty of New Sciences and Technologies, University of Tehran, Tehran, Iran. He obtained his BS, MS, and PhD degrees from Amirkabir university of Technology up to 2008. His research interests are in the areas of vibration, aeroelasticity and composite material analysis.

Hassan Haddadpour is currently a Professor at Department of Aerospace Engineering, Sharif University of Technology, Tehran, Iran. He obtained his MS, and PhD degrees from University of Tehran up to 2002. His research interests are in the areas of aeroelasticity, structural dynamics, reduced order modeling, structural design of aerospace vehicles and aeroservoelasticity.

Hossein Tuzandejani is currently a PhD Student at Department of Aerospace Engineering, Sharif University of Technology, Tehran, Iran. His research interests are in the areas of vibration and composite material analysis.

Seyyed Ali Asghar Hosseini is currently an Assistant Professor at Faculty of Engineering, Kharazmi University, Tehran, Iran. He have been obtained his BS 
degree from University of Science and Technology, and MS and PhD degrees from Tarbiat Modares University. His research interests are in the areas of nonlinear vibrations, nonlinear dynamics, random vibrations, and rotor dynamics.

Mohsen Vatanparast is a MSc student graduated from the Department of Mechanical Engineering, Iran
University of Science \& Technology, Tehran, Iran. His research interests are in the areas of vibration and composite material analysis.

Saleheh Zahab is an MSc student graduated from Aerospace Engineering Department, Amirkabir University of Technology, Tehran, Iran. His research interests are in the areas of vibration and aeroelasticity. 